\title{
New Developments in Cationic Polymerization of Cyclosiloxanes
}

\author{
Dedicated to the Memory of the late Professor Ichiro Sakurada \\ Pierre SIGWALT \\ Université Pierre et Marie Curie, Laboratoire de Chimie Macromoléculaire, \\ 4, Place Jussieu-75252 Paris, Cédex 05, France
}

(Received January 30, 1987)

\begin{abstract}
Some recent publications ${ }^{5-8}$ have shown the analogies or the differences in the behavior of cyclosiloxanes of various sizes (particularly $D_{3}$ and $D_{4}$ ) when they are initiated by triflic acid. They are discussed in the present article, the analogies being found mainly in the general kinetics, and the differences in the rates, in the nature of the cyclic oligomers formed, and in the effect of water on the reaction. New data are given, for $D_{3}$ polymerization, on the absence of reaction with triflate esters in the absence of acid or water, on the effect of water on polymerization and on the variation of the polymer mol wt with conversion. Even if it is too early to come to definite conclusions about the nature of the different types of active species, the various possibilities
\end{abstract} are discussed.

KEY WORDS Cyclosiloxanes Trifluoromethanesulfonic Acid methylcyclotetrasiloxane /
The main theoretical problem in cationic polymerization of cyclosiloxanes is that of the knowledge of the nature of the active species and of their concentration, and it is linked to the important practical question of the control of cyclic oligomers formation versus linear polymer formation. Protonic acids such as sulfuric acid or trifluoromethanesulfonic (triflic) acid have been generally used as cationic initiators, and the possibility of using nonprotonic initiators to give high polymers is still being discussed. The most extensive studies published until now have been made either with hexamethylcyclotrisiloxane $\left(D_{3}\right)^{1,2}$ or octamethylcyclotetrasiloxane $\left(\mathrm{D}_{4}\right)^{3,4}$ The polymerization of $D_{3}$ is much more rapid which has been assumd to result (as in anionic polymerization) from a higher ring strain. In a recent publication, ${ }^{5}$ it was concluded that these two monomers were polymerized by similar mechanisms and that the differ- ences could be explained by differences in hydrogen bonding, easier with the more "basic" $D_{3}$. The available publications and also some more recent data shall be discussed in the present article and lead us to somewhat different conclusions. We shall also examine the problem of the reactivity of triflic esters in these systems and also that of higher cyclosiloxanes $\left(D_{5}, D_{6}\right)$.

The main analogies and differences in the benavior of $D_{3}$ and $D_{4}$ may be observed in the kinetic equations, in formation of the high polymer and of the various cyclic species, and in the effect of added water on the reaction. ${ }^{6.7}$ They will be discussed successively for reactions initiated by triflic acid in methylene chloride solution at room temperature. 


\section{KINETICS OF $D_{3}$ AND $D_{4}$ POLYMERIZATIONS INITIATED WITH TRIFLIC ACID}

Even if polymerization of $\mathrm{D}_{3}$ in hydrocarbon solution (e.g., heptane) is in several respects quite similar, ${ }^{1,2}$ we shall give here and discuss briefly the results obtained in $\mathrm{CH}_{2} \mathrm{Cl}_{2}$ at room temperature, for which comparative data with $\mathrm{D}_{4}$ are available. One common feature for both monomers is that the internal order in monomer concentration is equal to 1 , as shown by the linearity of the first order plots of $\log \left\{\left[\mathrm{D}_{x}\right]_{0}-\left[\mathrm{D}_{x}\right]_{\mathrm{e}} /\left[\mathrm{D}_{x}\right]-\left[\mathrm{D}_{x}\right]_{\mathrm{e}}\right\}$ versus time, at least when conversions are not too high. $\left[D_{x}\right]_{0}$ is the initial and $\left[D_{x}\right]_{e}$ the final (equilibrium) monomer concentration, and the slope of such a plot is equal to $k_{p_{x}}\left[\mathrm{P}^{*}\right]$, if $\left[\mathrm{P}^{*}\right]$ is the concentration of growing chains.

When comparable data are available, there is a satisfactory agreement between the results obtained by the two different groups ${ }^{1-4}$ by which these studies were made.

For $\mathrm{D}_{4}$ the initial rate $R_{p_{0}}=k\left[\mathrm{D}_{4}\right]_{0}^{0.7}$. $[\mathrm{TfOH}]^{2.2}$ (in a range of $[\mathrm{D}]_{0}$ concentrations of 0.3 to $2.7 \mathrm{M}$ and of [TfOH $]_{0}$ from $1.5 \times 10^{-3}$ to $\left.1.2 \times 10^{-2} \mathrm{M}\right)^{3,4}$ and to $R_{p_{0}}=k[\mathrm{TfOH}]_{0}^{2}$ $\left([\mathrm{TfOH}]_{0}\right.$ from $10^{-4}$ to $\left.10^{-2} \mathrm{M}\right) .^{5}$ It should be pointed out that initial rates in the case of $D_{4}$ (and also for $D_{5}$ and $D_{6}$ ) are not representative of the main reaction. There is first a rapid monomer consumption giving various cyclic oligomers (sometimes with kinetic enhancement) ${ }^{18}$ and contrarily to the $D_{3}$ case, the first order plots obtained later on extrapolate higher than the origin. A more complex dependence of $R_{p_{0}}$ on $\left[\mathrm{D}_{4}\right]_{0}$ was found in ref 5 , the rate increasing with $[D]_{0}$ at the lower concentrations and decreasing at higher concentrations. But this was found for $\mathrm{CF}_{3} \mathrm{SO}_{3} \mathrm{H}$ concentrations lower than those used by Lebrun et al. , $^{3,4}$

Simpler and more precise results were obtained from the slope of the first order plots giving $k_{p}\left[\mathrm{P}^{*}\right]$. For $\mathrm{D}_{4}{ }^{4}\left[\mathrm{P}^{*}\right]=k[\mathrm{TfOH}]_{0}^{2.7} /$ $\left[\mathrm{D}_{4}\right]_{0}^{0.8}\left(\left[\mathrm{D}_{4}\right]_{0}\right.$ from 0.27 to $2.8 \mathrm{M}$ and
$\left[\mathrm{CF}_{3} \mathrm{SO}_{3} \mathrm{H}\right]_{0}$ from $1.5 \times 10^{-3}$ to $\left.1.2 \times 10^{-2} \mathrm{M}\right)$, and for $\mathrm{D}_{6},{ }^{18}\left[\mathrm{P}^{*}\right]=k[\mathrm{TfOH}]_{0}^{2.7}$.

For $\mathrm{D}_{3}, R_{p}{ }^{\circ}$ has been found respectively equal to $k\left[\mathrm{CF}_{3} \mathrm{SO}_{3} \mathrm{H}\right]_{0}^{2} /\left[\mathrm{D}_{3}\right]^{0.75}$ and to $k\left[\mathrm{CF}_{3} \mathrm{SO}_{3} \mathrm{H}\right]_{0}^{2.1} /\left[\mathrm{D}_{3}\right]^{0.6}$. ${ }^{9}$ For the same monomer the $\mathrm{P}^{*}$ concentration $^{9}$ varies much more with $\left[\mathrm{D}_{3}\right]_{0}$ than what was observed with $\mathrm{D}_{4}:\left[\mathrm{P}^{*}\right]=k[\mathrm{TfOH}]_{0}^{3} /\left[\mathrm{D}_{3}\right]_{0}^{1,8}\left(\left[\mathrm{D}_{4}\right]_{0}\right.$ from 0.42 to $1.63 \mathrm{M}$ and $\left[\mathrm{CF}_{3} \mathrm{SO}_{3} \mathrm{H}\right]_{0}$ from $5 \times 10^{-4}$ to $\left.1.2 \times 10^{-3} \mathrm{M}\right){ }^{9}$

The differences observed in the $R_{p_{0}}$ for these two monomers reflect probably the large variation in rates and the longer time needed with $\mathrm{D}_{4}$ to reach a stationary concentration of active species. The $\mathrm{P}^{*}$ values are more precise and probably more significant. A common feature for these two monomers (found also for $\mathrm{D}_{6}$ ) is the high order in $[\mathrm{TfOH}]_{0}$ from 2.7 to 3. An explanation of this order has been that only higher aggregates (dimers or trimers) could initiate the polymerization, but their presence in large amount seems unlikely at the concentration used, and moreover in the presence of monomers that may complex with the acid. However, the ring opening of $\mathrm{D}_{x}$ may necessitate two acid molecules, reacting successively. This might lead to an active centre (or end-group) concentration proportional to $[\mathrm{TfOH}]_{0}^{2}$. But to explain a higher order, it seems necessary to admit that $\mathrm{TfOH}$ is also involved in the propagation step.

\section{FORMATION OF SMALL CYCLES IN POLYMERIZATION OF CYCLOSILOXANES}

With both $D_{3}$ and $D_{4}$, large quantities of other small cycles are formed simultaneously with the high polymer. This situation has been also observed in other ring-opening polymerizations and has been generally assigned to reactions of active centers with heteroatoms of the polymer chain (back-biting) or with the other end-goup (end-biting). These phenomena may be particularly important with cyclosiloxanes because a relatively large cycle may 
have a reactivity very similar to that of a linear chain. This may also lead to some redistribution of the chain lengths of the linear polymer. The main effect is however that of the competitive reformation of cycles by a "back-biting" reaction., If the reaction is carried out long enough for an equilibrium situation to be observed, to each cycle $D_{x}$ present should correspond an equilibrium constant for the reaction

$$
-\mathrm{D}_{\bar{n}} \stackrel{K_{x}}{\rightleftarrows}-\mathrm{D}_{\bar{n}-x}+\mathrm{D}_{x} .
$$

For long chains, the equilibrium concentration $\left[\mathrm{D}_{x}\right]_{\mathrm{e}}=K_{x}$. It has been found experimentally in anionic polymerizations that $\left[D_{x}\right]_{e}$ values are practically independent of temperature (except for $\left[\mathrm{D}_{3}\right]_{\mathrm{e}}$ ) showing that $K_{x}$ is determined by entropic factors. ${ }^{6,10}$ The general theory of Jacobsen and Stockmayer ${ }^{11}$ has led to the conclusion that if there is no excluded volume effect, if the rings are all strainless and if the probability of ring formation is only governed by the frequency of coincidence between end-group and a unit of the chain, $K_{x}$ is linked to $x$ by the following equation: $K_{x}=A x^{-5 / 2}$. The plot of $\log K_{x}$ versus $\log x$ has given a slope very near -2.5 for $x$ equal to or higher than $16 .^{10}$ The same relationship may also be deduced from kinetic considerations ${ }^{12}$ if one assumes the rate constant of propagation $k_{p_{x}}$ to be proportional to $x$ (number of $\mathrm{D}$ units) and that of depropagation $k_{x}$ (by a "backbiting" mechanism) to be proportional to $x^{-3 / 2}$ as has been calculated by $\mathrm{Kühn}^{13}$ assuming Gaussian statistics. Then $K_{x}=k_{x} /$ $k_{p_{x}}=K x^{-5 / 2}$. But for the lower values of $x$, rather large discrepancies have been observed with siloxanes, $K_{x}$ being lower than theoretical values for $x$ between 8 and 16 and much larger than theoretical for $x \leqslant 7$. These discrepancies were however hoped to be resolved by introducing some corrections in the cyclization rate. $^{12}$

For $\mathrm{D}_{4}$ polymerization, the equilibrium concentration of cycles $D_{x}$ is progressively reached in a few hours, together with the polymer concentration at equilibrium. The situation is quite different for $\mathrm{D}_{3} \cdot{ }^{1,2,9}$ Both polymer and cycles are formed much more rapidly, and the type of cycles is completely different during most of the reaction, being exclusively of the $D_{3 n}$ type (that is, $D_{6}, D_{9}, D_{12} \cdots$ ) cycles with $3 n+1$ and $3 n+2$ units being formed very slowly (and more slowly in heptane than in $\left.\mathrm{CH}_{2} \mathrm{Cl}_{2}\right){ }^{1,2}$ An equilibrium situation with $\mathrm{D}_{3}$ will be examined later, and we shall see first what happens in the polymerizations of $D_{4}$, $\mathrm{D}_{5}$, and $\mathrm{D}_{6}$.

\section{RATE CONSTANTS FOR PROPAGATION AND FOR BACK-BITING IN \\ POLYMERIZATIONS OF $\mathrm{D}_{4}, \mathrm{D}_{5}, \mathrm{D}_{6}$}

The reactivities according to the size of the cycle are not well understood. Some data of anionic polymerizations have shown that the rate constant of propagation is not simply related to the number of $\mathrm{D}$ units. For polymerization of various $D_{x}$ initiated with potassium hydroxide, a minimum in reactivities was found for $\mathrm{D}_{4}$ and $\mathrm{D}_{5},{ }^{14}$ the order of increasing reactivities being $D_{4}<D_{5}<D_{6}<D_{3}<D_{7} \sim D_{8}$ and a similar situation was observed for the reactivities of the same monomers with a potassium silanolate. ${ }^{15}$ Two interpretations of these results have been proposed: either a specific coordination of the counter ion involving all the oxygens of the ring and permitting an easier dissociation of the ion pair in the transition state, ${ }^{15}$ or the formation with the silanolate of a coordination intermediate that would be easier for more flexible rings. ${ }^{14}$

No comparable data in cationic polymerization were available for the dimethylsiloxane series $\left(\left(\mathrm{CH}_{3}\right)_{2} \mathrm{SiO}\right)_{x}$. However, an increase of the global rate when $x$ increased from 5 to 7 had been shown to occur for the $\left(\mathrm{CH}_{3}(\mathrm{H}) \mathrm{SiO}\right)_{x}$ series (initiation by $\mathrm{CH}_{3} \mathrm{SO}_{3} \mathrm{H}$ ). ${ }^{16}$

The interpretation of all these data were however difficult since global rates involve 
initiation, propagation and possibly termination steps and do not reflect necessarily the monomer reactivities. The ratios of their propagation rate constants may be however obtained by following the concentration of the various cycles with time.

During $\mathrm{D}_{6}$ polymerization by triflic acid, ${ }^{8}$ it was found that the concentrations of $D_{4}$ and $\mathrm{D}_{5}$ increased slowly up to their equilibrium values, and that the polymer was formed rapidly after a short induction period.

By assuming a propagation of first order for the various monomers concentration and for the active centers $\left[\mathrm{P}_{n}^{*}\right]$ concentration, the following equation is easily deduced:

$$
\log \frac{\left[\mathrm{D}_{x}\right]_{0}-\left[\mathrm{D}_{x}\right]_{\mathrm{e}}}{\left[\mathrm{D}_{x}\right]-\left[\mathrm{D}_{x}\right]_{\mathrm{e}}}=k_{p_{x}}\left[\mathrm{P}_{n}^{*}\right] t
$$

where $\left[D_{x}\right]_{0}$ is the initial concentration and $\left[D_{x}\right]_{e}$ the concentration at equilibrium for any cycle $\mathrm{D}_{x}$. $\left[\mathrm{D}_{x}\right]_{\mathrm{e}}=k_{x} / k_{p_{x}}$, and eq 1 may be used for the monomer $\left(\left[D_{x}\right]_{0} \neq 0\right)$ as well as for other cycles $\left(\left[D_{x}\right]_{0}=0\right)$. The plots of eq 1 for $D_{6}$ consumption and for $D_{4}$ and $D_{5}$ formation were found to be linear, which shows that $\left[\mathrm{P}_{n}^{*}\right]$ is constant. From the slope, the product $k_{p_{x}}$. $\left[\mathrm{P}_{n}^{*}\right]$ was obtained and, for each experiment, the various ratios of propagation rate constants. ${ }^{8}$ Similar results could be obtained from $D_{4}$ polymerizations, and all the ratios are in good agreement: $k_{p 5} / k_{p 4} \sim 2.1 \pm 0.4$ and $k_{p 6} / k_{p 4}=$ $5.8 \pm 1.2$, which means that $D_{5}$ is twice as reactive and $D_{6}$ six times as reactive as $D_{4}$. It may also be noted that the global rates of polymerization of $D_{4}, D_{5}$, and $D_{6}$ (for the same acid concentration) varied approximately in the same way, which shows that the active centers concentrations were similar. The situation is thus analogous with what was observed for global rate constants in some anionic polymerizations and probably reflects some conformational effect on the ease of formation of the transition state. The backbiting rate constants were not found significantly different for the formation of $D_{4}, D_{5}$, and $D_{6}$. This confirms that at least for those monomers, the main kinetic factor controlling the cycles concentration at equilibrium is not their rates of reformation, but their rates of consumption.

\section{FORMATION OF THE CYCLES $D_{3 x}$ IN THE POLYMERIZATION OF $\mathrm{D}_{3}$}

The exclusive formation of cycles $\mathrm{D}_{3 x}$ in the polymerization of $D_{3}$ (at least at the beginning of the reaction) has been attributed by Chojnowski et al. ${ }^{1}$ to competition between a normal growth of the polymer on reactive centres $\mathrm{A}$ and an end-to-end ring closure of $\mathrm{A}$ with the functional group B (presumably $\mathrm{OH}$ ) situated at the other end:

$$
\mathrm{BD}_{3} \mathrm{~A} \underset{\mathrm{D}_{3}}{\stackrel{k_{p}}{\longrightarrow}} \mathrm{BD}_{6} \mathrm{D}_{\mathrm{D}_{6}} \mathrm{~A} \underset{\mathrm{D}_{6}}{\stackrel{k_{p}}{\longrightarrow}} \mathrm{BD}_{9} \mathrm{DD}_{9} \mathrm{~A} \stackrel{k_{p}}{\longrightarrow}
$$

The reason for the preference for ring closure comparatively to back-biting was attributed to a reactivity of the active center with the terminal group larger than that with the monomer, so that propagation is relatively unfavored and occurs only when the polymer chain is long enough (the probability of ring closure having strongly decreased). What is not clear is why, in the case of a less reactive monomer such as $\mathrm{D}_{4}$, the ring closure would not be still more favored if the same terminal groups were present.

The growth of the mol wt of the high polymer observed in the same experiments was attributed to intermolecular coupling reactions (e.g., between an ester or another "A" group and an $\mathrm{OH}$ of a different polymer molecule). However, we have studied recently more systematically the growth of mol wt in various conditions and found it to increase linearly with conversion and also with the weight of the polymer formed, from the beginning of the reaction (see Figure 1). This shows that the 


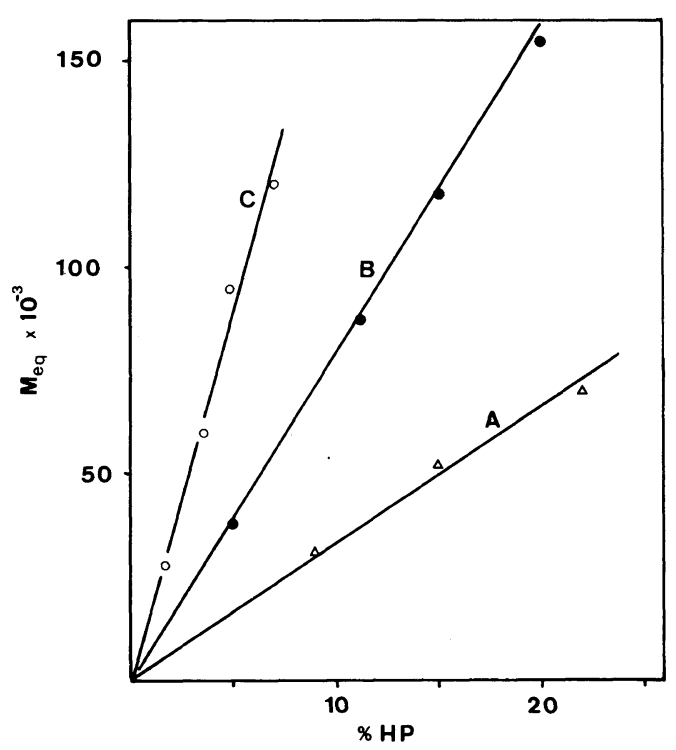

Figure 1. Variation of the mol wt of the polymer formed during the polymerization of $D_{3}$, with the yield of high polymer $\mathrm{HP}$. Polymerization at $20^{\circ} \mathrm{C}$ in methylene chloride, $\left[\mathrm{CF}_{3} \mathrm{SO}_{3} \mathrm{H}\right]_{0}=7 \times 10^{-4} \mathrm{M} ;\left[\mathrm{D}_{3}\right]_{0}$ concentrations: A, $0.42 \mathrm{M} ; \mathrm{B}, 0.92 \mathrm{M} ; \mathrm{C}, 1.63 \mathrm{M} . M_{\mathrm{eq}}=$ mol wt at the peak in the chromatogram in equivalent polystyrene.

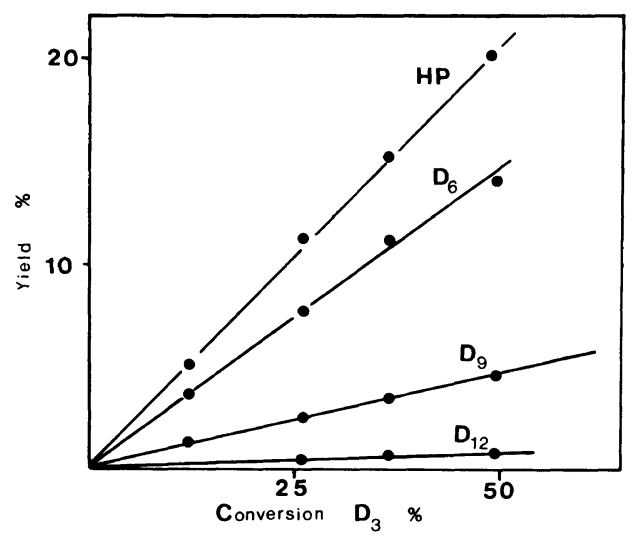

Figure 2. Yield (in $\%$ of $\left[D_{3}\right]_{0}$ ) in high polymer (HP), $\mathrm{D}_{6}, \mathrm{D}_{9}$, and $\mathrm{D}_{12}$ according to monomer conversion. Polymerization at $20^{\circ} \mathrm{C}$ in $\mathrm{CH}_{2} \mathrm{Cl}_{2}$ solution. $\left[\mathrm{D}_{3}\right]_{0}=$ $0.92 \mathrm{M} ;\left[\mathrm{CF}_{3} \mathrm{SO}_{3} \mathrm{H}\right]_{0}=7 \times 10^{-4} \mathrm{M}$.

number of macromolecules remains constant during the polymerization. This number is about 30 to $40 \%$ of the number of acid molecules used in the experiments corresponding

\section{to Figures 1 and 2.}

As had been found earlier by Chojnowski et $a .^{2}$ we observed a linear growth of $\mathrm{D}_{6}$ and $\mathrm{D}_{9}$ concentrations with conversion and with polymer yield (see Figure 2). According to the above scheme proposed by Chojnowski et al., ${ }^{1}$ a formation of cycles $\mathrm{D}_{3 x}$ proportional to polymer yield necessitates the continuous formation of new growing chains, i.e., initiation during the whole reaction, which does not agree with a constant number of growing macromolecules. In a theoretical study of ring formation by ring closure simultaneous to chain polymerization, Penczek et al. also came to the conclusion that cycles $\mathrm{D}_{3 x}$ formed by ring closure should dominate at the early stages of polymerization and that their relative concentration should then decrease. ${ }^{12}$

To explain what is observed in this system, in which $\mathrm{D}_{3 x}$ molecules are formed in an amount exactly proportional to the polymer yield (Figure 2), there seems to be two possibilities. The formation of the polymer and of the small cycles might result from different reactions occurring either at constant concentrations of two different active sites, or on only one kind of active site giving either the polymer or the cyclic oligomers. These various possibilities will be discussed later, but whatever is the case for high polymer growth, the formation of the $\mathrm{D}_{3_{x}}$ by a ring expansion should be considered.

One argument given against ring expansion was that "the structure of the active centre should differ for various catalysts and in various media". "In fact, this is what has been observed as well by Chojnowski et al. ${ }^{1}$ (e.g., a large variation of the $\left[\mathrm{D}_{9}\right] /\left[\mathrm{D}_{6}\right]$ ratio according to initiator) as by ourselves with non-protonic initiators ${ }^{9}$ for which a much higher proportion of $\mathrm{D}_{6}$ and $\mathrm{D}_{9}$ relatively to polymer was formed. The main argument against ring expansion was that the concentration of the ${ }^{\circ} D_{3 x}$ rings was found to correlate well with the conformational probability $p$ of the ring closure: $p \sim n^{-1.5}$. However, this was 
approximatively observed only for very large rings ( $x$ between 18 and 30) which might be formed in a different way than $D_{6}$ and $D_{9}$.

But since end-to-end ring closure cannot explain the results discussed above for $D_{6}$ and $D_{9}$, the most likely possibility for the formation of large quantities of $\mathrm{D}_{3 x}$ cycles, together with a high polymer in constant molar concentration, seems to be a ring expansion occurring on oxonium sites of the $\mathrm{D}_{3}^{+}$type:

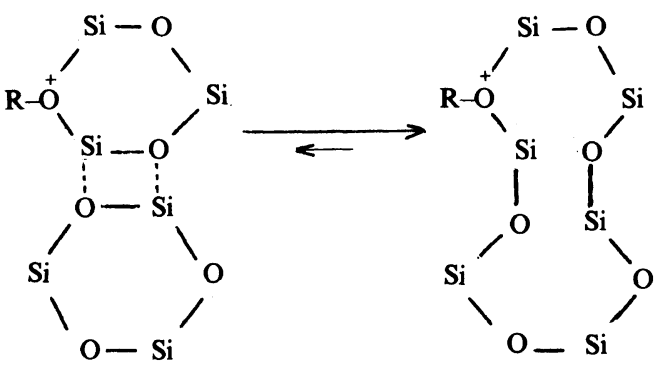

Once $\mathrm{D}_{6}^{+}$is formed, it would exchange with the more basic $D_{3}$ to liberate $D_{6}$, giving back the $\mathrm{D}_{3}^{+}$oxonium ion, or it might expand again giving $\mathrm{D}_{9}^{+}$, and so on. An indirect but strong argument in favor of a transition state such as that written above is that in the polymerization of $D_{6}$ with triflic acid, there was at the beginning a very rapid formation of $\mathrm{D}_{3}$ in a concentration higher than its equilibrium value (kinetic enhancement) that might result from the reverse reaction starting from the oxonium $\mathrm{D}_{6}^{+} \cdot{ }^{8}$ In $\mathrm{D}_{3}$ polymerization, we also found that the concentration of $D_{5}$ formed slowly (comparatively to $\mathrm{D}_{6}$ or $\mathrm{D}_{9}$ ) in $\mathrm{CH}_{2} \mathrm{Cl}_{2}$ solution, was always much larger than that of $\mathrm{D}_{4}$, which is contrary to what would be expected if they were both made through a back-biting mechanism. This might eventually be explained if they were formed mainly by a similar ring-contraction mechanism:

$$
\mathrm{D}_{9}^{+} \longrightarrow \mathrm{D}_{4}+\mathrm{D}_{5} ; \quad \mathrm{D}_{12}^{+} \longrightarrow \mathrm{D}_{7}+\mathrm{D}_{5}
$$

\section{ROLE OF TRIFLIC ESTERS IN THE POLYMERIZATION OF $\mathrm{D}_{3}$ AND $_{4}$}

For $\mathrm{D}_{3}$ polymerization, it had formerly been concluded by Chojnowski et al. that triflic esters are not able by themselves to open the siloxane bond. This was based on the near zero extrapolation of the reaction rate of $\mathrm{D}_{3}$ at decreasing water concentration in the system. But since we have found a more complex behavior of the rate for low water concentration (see next section) it was interesting to check directly this assumption and it was in fact shown to be correct. When trimethylsilyl triflate (TMST) was added to $\mathrm{D}_{3}$ and $\mathrm{CH}_{2} \mathrm{Cl}_{2}$ carefully purified over several sodium films, a very slow reaction occurred probably resulting from the presence of traces of acid in the ester. But when the ester was reacted with about $5 \%$ of 4-methyl-2,6-di-tert-butylpyridine (MDTBP) just before its addition, no reaction occurred even at high concentration of ester $\left(\left[\mathrm{D}_{3}\right]_{0}: 1.05 \mathrm{M} \text {; [ester }\right]_{0}: 5.7 \times 10^{-2} \mathrm{M}$; $\left.[\mathrm{MDTBP}]_{0}: 3 \times 10^{-3} \mathrm{M}\right)$. However, with the same ester concentration and addition of $1.37 \times 10^{-3} \mathrm{M}$ of $\mathrm{CF}_{3} \mathrm{SO}_{3} \mathrm{H}$, the reaction was very rapid, giving a very low polymer ( $\bar{M}_{\text {equ }} \sim 2000$ only). There is a strong cocatalytic effect of the ester for the initiation with the acid, but in the absence of acid, the ester is completely inactive.

Similar results had been obtained formerly by Lebrun et al., ${ }^{3,4}$ for the less reactive $\mathrm{D}_{4}$ also in $\mathrm{CH}_{2} \mathrm{Cl}_{2}$ at $20^{\circ} \mathrm{C}$. No reaction occurred in the presence of the triflic ester when the proton trap MDTBP was added $\left(\left[\mathrm{D}_{4}\right]_{0}: 0.97 \mathrm{M}\right.$; $[\text { ester }]_{0}: 5 \times 10^{-2} \mathrm{M}$; [MDTBP] $\left.]_{0}: 10^{-3} \mathrm{M}\right)$. The cocatalytic effect of TMST on the initiation of $\mathrm{D}_{4}$ with triflic acid has also been shown: the addition of an equimolar amount of the acid $\left(\left[\mathrm{D}_{4}\right]_{0}: 0.97 \mathrm{M} \text {; - [ester }\right]_{0}: 6.5 \times 10^{-3} \mathrm{M}$; [acid] $]_{0}$ : $5.8 \times 10^{-3} \mathrm{M}$ ) multiplied the initiation rate by a factor of 2.5 , and suppressed completely the high polymer formation. This was given as an argument for a mechanism of the formation of the high polymer in the case of 
$\mathrm{D}_{4}$ involving polycondensation of the low polymer. When TMST was added, it was assumed that initiation involved an activation of the ester by the acid and led to $\left(\mathrm{CH}_{3}\right)_{3} \mathrm{SiO}$ end group:

$$
\begin{aligned}
& \mathrm{CF}_{3} \mathrm{SO}_{3} \mathrm{Si}\left(\mathrm{CH}_{3}\right)_{3}, \mathrm{CF}_{3} \mathrm{SO}_{3} \mathrm{H}+\mathrm{D}_{4} \\
& \stackrel{\mathrm{D}_{4}}{\longrightarrow}\left(\mathrm{CH}_{3}\right)_{3} \mathrm{Si}\left(\mathrm{D}_{4}\right) \mathrm{OSO}_{2} \mathrm{CF}_{3}, \mathrm{CF}_{3} \mathrm{SO}_{3} \mathrm{H} \\
& \longrightarrow \text { Polymer }
\end{aligned}
$$

But one might also consider the possibility of a polymer growth involving the ester and the activated monomer:

$$
\begin{aligned}
& \mathrm{CF}_{3} \mathrm{SO}_{3} \mathrm{Si}\left(\mathrm{CH}_{3}\right)_{3}+\mathrm{D}_{4}, \mathrm{HSO}_{3} \mathrm{CF}_{3} \longrightarrow \\
& \left(\mathrm{CH}_{3}\right)_{3} \mathrm{Si}\left(\mathrm{D}_{4}\right) \mathrm{OSO}_{2} \mathrm{CF}_{3}+\mathrm{CF}_{3} \mathrm{SO}_{3} \mathrm{H} \text {, etc. }
\end{aligned}
$$

In both cases, the initial presence of TMST may lead to faster initiation than when the silyl esters are made "in situ" (in absence of TMST) and to a larger number of low mol wt macromolecules with one $\left(\mathrm{CH}_{3}\right)_{3} \mathrm{SiO}$ end group and one ester group, instead of the 2 ester groups formed in absence of TMST. This would prevent the polycondensation, possible in that last case with the silanol group formed by hydrolysis of one of the ester group by water in equilibrium, or resulting from a termination reaction involving water. It was indeed observed that the polymer formed in the presence of the ester (in concentration equal to that of the acid) had a mol wt of about 5000 instead of 22000 in its absence.

\section{ROLE OF ADDED WATER ON POLYMERIZATIONS OF $\mathrm{D}_{3}, \mathrm{D}_{4}$ AND $\mathrm{D}_{6}$ INITIATED BY TRIFLIC ACID}

The unexpected and very strong cocatalytic effect of added water on the rate of polymerization of $\mathrm{D}_{3}$ has been discovered by Chojnowski et al. ${ }^{2}$ For example, the apparent rate constants $k_{p}\left[\mathrm{P}^{*}\right]$ in $\mathrm{CH}_{2} \mathrm{Cl}_{2}$ solution increased by a factor of $10^{2}$ to $10^{3}$ when the ratios $\left[\mathrm{H}_{2} \mathrm{O}\right]_{0} /\left[\mathrm{CF}_{3} \mathrm{SO}_{3} \mathrm{H}_{0}\right.$ increased from zero to $30\left(\left[\mathrm{CF}_{3} \mathrm{SO}_{2} \mathrm{H}\right]_{0}=2.1 \times 10^{-4} \mathrm{M}\right)$, or from zero to 10 (for $\left[\mathrm{CF}_{3} \mathrm{SO}_{3} \mathrm{H}\right]_{0}=7 \times 10^{-4} \mathrm{M}$ ). Two different though not exclusive explanations have been proposed of these results ${ }^{2,7}$ : first, the possible hydrolysis of the triflate ester by the reaction

$$
\sim \mathrm{SiOSO}_{2} \mathrm{CF}_{3}+\mathrm{H}_{2} \mathrm{O} \rightleftarrows \sim \mathrm{SiOH}+\mathrm{CF}_{3} \mathrm{SO}_{3} \mathrm{H} .
$$

The liberated $\mathrm{CF}_{3} \mathrm{SO}_{3} \mathrm{H}$ was assumed to activate silanol groups giving

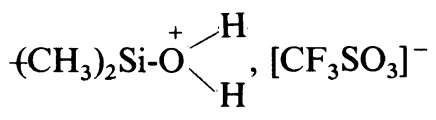

which were considered the most likely active centers. $^{2,5}$. However, the very sharp increase in rate at higher water concentrations has also been attributed to a supplementary effect of water. ${ }^{2)}$ The addition of an acid activated monomer to the silanol end group was also considered in the systems containing more water, ${ }^{5}$ which would imply that hydration of an acid-monomer complex would increase strongly its reactivity.

Such an activation has been suggested by Chojnowski et al. ${ }^{19}$ to result from the increase of both acidity and nucleophilicity of the hydrate:

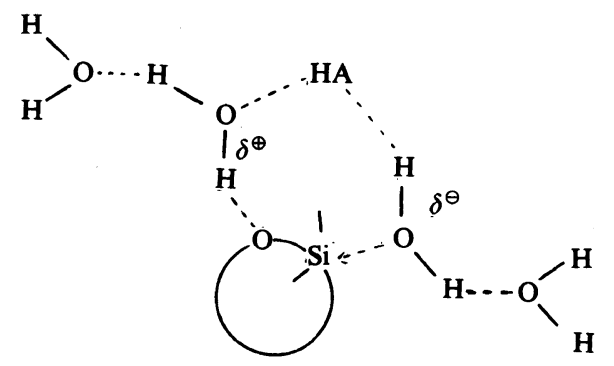

For $\mathrm{D}_{4}$ polymerizations in $\mathrm{CH}_{2} \mathrm{Cl}_{2}$ solution, the effect of initial water concentration was found completely different and even apparently opposite. ${ }^{3,4}$ Reactions were made at acid concentrations higher than for $D_{3}(1.5$ to $\left.6 \times 10^{-3} \mathrm{M}\right)$ since they are necessary in order to obtain high polymer in reasonable time (a few hours) with this much less reactive monomer. With a molar ratio $r=$ [water]/[acid] of 1 , the initial rate decreased by a factor of 2 and for $r=10$, the rate become negligible, no poly- 
mer being obtained after 3 days (and only $9 \%$ of small cycles and $3 \%$ of macrocycles) (both experiments with $[\mathrm{M}]_{0}=0.96 \mathrm{M}$ and $\left.\left[\mathrm{CF}_{3} \mathrm{SO}_{3} \mathrm{H}\right]_{0}=5.8 \times 10^{-3} \mathrm{M}\right)$. Since we suspected a possible competition for the acid between $\mathrm{D}_{4}$ and water initially present during the first seconds of the reaction, we have recently conducted experiments in which the preformed monohydrate of the acid was used. ${ }^{18}$ The rates were much smaller than with an initial $r$ value of 1 . For a monohydrate concentration of $1.56 \times 10^{-3} \mathrm{M}$ the rate was 12 times lower than without added water and the high polymer and macrocycles appeared only after $25 \mathrm{~h}$. When a lower concentration of hydrate $\left(0.55 \times 10^{-3} \mathrm{M}\right)$ was used, there was a long induction period for the formation of the small cycles and macrocycles and the high polymer was never formed. This shows clearly the inhibitory effect of water on the polymerization of $\mathrm{D}_{4}$. For $\mathrm{D}_{6}$ polymerization with the monohydrate, similar results ${ }^{18}$ were obtained at higher acid concentration (e.g., $5.5 \times 10^{-3} \mathrm{M}$ of hydrate) for the initial rate that decreased by a factor of about 7. However, there was only an induction period for the formation of the high polymer which was not inhibited. This reflects the higher reactivity of $D_{6}$ compared to $D_{4}$ and its behavior intermediate between those of $\mathrm{D}_{4}{ }^{8,18}$

For $\mathrm{D}_{3}$ polymerization, results have been found recently ${ }^{9}$ to be more complex than in the earlier studies. ${ }^{2}$ For the high $r$ values, the two sets of data are similar: e.g., for $\left[\mathrm{CF}_{3} \mathrm{SO}_{3} \mathrm{H}\right]_{0}=$ $1.3 \times 10^{-3} \mathrm{M}$, an increase of the rate by a factor of 20 for $r=10$. However, for low water concentrations, there was first a decrease of the apparent rate constant (i.e., of the $\left[\mathrm{P}^{*}\right]$ ), by a factor of 5 for $r=1$ and by a factor of 2 for $r=2$ (see Figure 3). The inhibitory effect of water at low concentration is thus similar to what was observed with $\mathrm{D}_{4}$, but at high $r$ values (e.g., about 10) the effect is completely opposite: inhibition for $\mathrm{D}_{4}$, strong catalysis for $\mathrm{D}_{3}$.

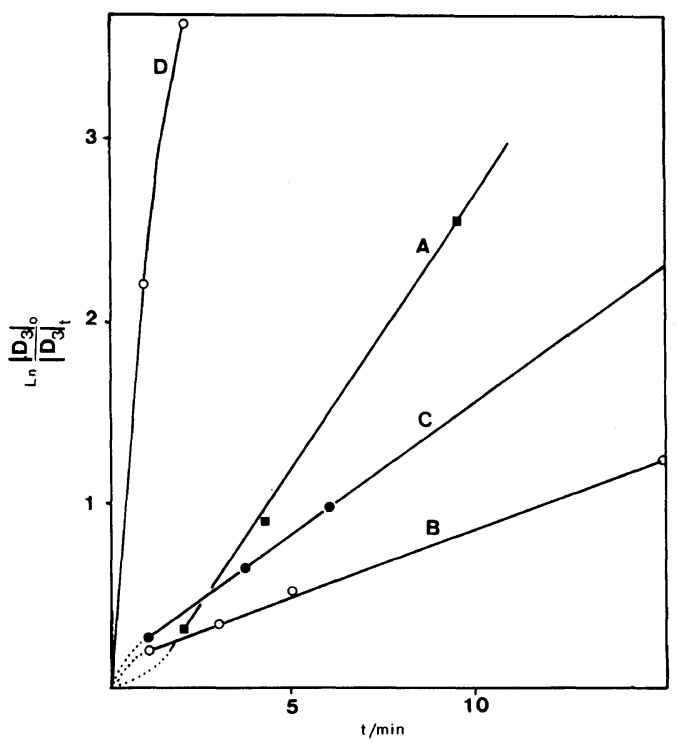

Figure 3. Influence of the concentration of added water on the rate of $D_{3}$ polymerization. Curve $A$, no added water; curve $\mathrm{B}, \mathrm{C}$, and $\mathrm{D}$, with added water in the monomer solution. $\left[\mathrm{D}_{3}\right]_{\mathrm{o}}: \mathrm{A}, 1.01 \mathrm{M} ; \mathrm{B}, 1.02 \mathrm{M}$; C, $1.04 \mathrm{M} ; \mathrm{D}, 1.09 \mathrm{M}$. $\left[\mathrm{CF}_{3} \mathrm{SO}_{3} \mathrm{H}\right]_{\mathrm{o}} \times 10^{3}: \mathrm{A}$ and $\mathrm{B}$, $1.25 \mathrm{M}$; C, $1.20 \mathrm{M} ; \mathrm{D}, 1.14 \mathrm{M}$. $\left[\mathrm{H}_{2} \mathrm{O}\right] \times 10^{3}: \mathrm{B}, 1.37 \mathrm{M}$; C, $2.6 \mathrm{M} ; \mathrm{D}, 11.8 \mathrm{M}$.

Apparently, hydrolysis of the ester by water leading to the formation of $\mathrm{CF}_{3} \mathrm{SO}_{3} \mathrm{H}$ cannot explain the respective variation in rates for $\mathrm{D}_{3}$ and $\mathrm{D}_{4}$, contrarily to what has been concluded in ref 5 , since hydrolysis of the ester groups by the excess water present might be expected to occur similarly in both cases. New experiments by Chojnowski et al. with $\mathrm{D}_{4},{ }^{5}$ but with lower $\left[\mathrm{CF}_{3} \mathrm{SO}_{3} \mathrm{H}\right]_{0}$ concentrations than those of Lebrun et al. $\left(2 \times 10^{-4}\right.$ and $7 \times 10^{-4} \mathrm{M}$ instead of $5.8 \times 10^{-3} \mathrm{M}$ ) showed an increase of the rate of $\mathrm{D}_{4}$ polymerization for respective $r$ values of 20 and 10 , but this increase was only by a factor of 3 instead of the much higher factor observed for $D_{3}$. These data are not necessarily contradictory with those of Lebrun described above: In Figure 3 of ref 5, it may be seen that for the same. water concentration $\left(7 \times 10^{-3} \mathrm{M}\right)$ the rates are higher than without water for acid concentrations lower than $3 \times$ $10^{-3} \mathrm{M}$, but that extrapolation of the $\log [\mathrm{R}]_{0}$ versus $\log \left[\mathrm{CF}_{3} \mathrm{SO}_{3} \mathrm{H}\right]_{0}$ plot would give a lower 
rate for an acid concentration of $7 \times 10^{-3} \mathrm{M}$ (equal to the water concentration in these experiments). The lowering would be by a factor of 2 , for [acid] $=7 \times 10^{-3} \mathrm{M}$, similar to that observed by Lebrun (with $5.8 \times 10^{-3} \mathrm{M}$ of acid and of water). It then seems that the cocatalytic effect of water is very small for $\mathrm{D}_{4}$ and effective only for relatively low $\left[\mathrm{CF}_{3} \mathrm{SO}_{3} \mathrm{H}\right]_{0}$ concentrations and high $r$ ratios, for which hydrolysis would effectively occur significantly.

The hydrolysis of the ester by water is not easy and necessitates large quantities of water. It has been shown Chojnowski et al. ${ }^{20}$ in their studies of the reactions of trifluoroacetic acid with siloxanes and silanols, that the equilibrium

$$
\begin{aligned}
\left(\mathrm{CH}_{3}\right)_{3} \mathrm{SiOCOCF}_{3}+ & \mathrm{H}_{2} \mathrm{O} \stackrel{K_{h}}{\rightleftarrows} \\
& \left(\mathrm{CH}_{3}\right)_{3} \mathrm{SiOH}+\mathrm{CF}_{3} \mathrm{CO}_{2} \mathrm{H}
\end{aligned}
$$

is shifted to the left, the $K_{h}$ value being about $5 \times 10^{-2}$. For the stronger triflic acid, $K_{h}$ should be still lower ${ }^{21}$ as recognized by Chojnowski et al. In fact, the real equilibrium in polymerization conditions is not between the ester and water but between the ester and hydrated acid.

$$
\begin{aligned}
& \sim \mathrm{SiOTf}+\mathrm{CF}_{3} \mathrm{SO}_{3} \mathrm{H}, n \mathrm{H}_{2} \mathrm{O} \rightleftarrows \\
& \sim \sim \mathrm{SiOH}+2\left(\mathrm{CF}_{3} \mathrm{SO}_{3} \mathrm{H}, \quad\left(\frac{n-1}{2}\right) \mathrm{H}_{2} \mathrm{O}\right)
\end{aligned}
$$

In the polymerization of $\mathrm{D}_{4}$, the water concentration for experiments made with $\left[\mathrm{CF}_{3} \mathrm{SO}_{3} \mathrm{H}\right]_{0}=5 \times 10^{-2} \mathrm{M}$ and $\mathrm{D}_{4}=1 \mathrm{M}$ was found to correspond to the hydrate $\mathrm{CF}_{3} \mathrm{SO}_{3} \mathrm{H} \cdot 7 \mathrm{H}_{2} \mathrm{O}$, in agreement with a remaining acid concentration of $7 \%$ of $\left[\mathrm{CF}_{3} \mathrm{SO}_{3} \mathrm{H}\right]_{0} \cdot{ }^{4}$ Apparently, hydrolysis of the ester groups (in large excess) might occur only with higher hydrates in which the nucleophilicity of water becomes high enough.

Some NMR experiments made with $D_{3}$ (however with lower monomer concentrations) seem to show that the transformation of the acid into ester (+water) is less com- plete than for $D_{4}$, which is opposite to the hypothesis that the acid is more converted into ester starting from $\mathrm{D}_{3}$, that was proposed to explain the much higher enhancement on water addition observed for $\mathrm{D}_{3}{ }^{5}$

How is it possible to understand why the initial ring opening reaction is more limited for $\mathrm{D}_{3}$, which is intrinsically a more reactive monomer than $\mathrm{D}_{4}$ in the same conditions (as has been observed in copolymerization experiments initiated by $\mathrm{CF}_{3} \mathrm{COOH}^{19}$ or by $\left.\mathrm{CF}_{3} \mathrm{SO}_{3} \mathrm{H}^{9}\right)$ ? A possibility could be that as soon as a quantity of water corresponding to about one or two moles per mole of acid is present (around $70 \%$ conversion of the acid into ester) it would form a mixed ternary complex $D_{3}$, $\mathrm{H}_{2} \mathrm{O}$, HA with the acid and $\mathrm{D}_{3}$ in which the acid would be much less reactive than "free" acid for the opening of $D_{3}$.

If initiation giving the active centers involves preferentially the complex $\mathrm{D}_{3}, \mathrm{HA}$ and a second molecule of HA, the probability of this reaction would decrease if a small quantity of water is already present, and this would explain the limited inhibitory effect observed for a $r$ ratio of 1 . When water in higher proportion is present in the system, it may be able to react with the above complex, either liberating hydrated acid or giving higher complexes, more reactive for the polymerization of $D_{3}$ (but not of $D_{4}$ ).

The inhibition also observed with $\mathrm{D}_{4}$ for $r=1$ might be explained in a similar way, but the decreased rate with higher values of $r$ shows that a different propagation mechanism should be considered for $\mathrm{D}_{4}$. The difference in the nature of the active species should also explain the nature of the various types of cycles, $D_{x}$ for $D_{4}$ and $D_{3 x}$ for $D_{3}$.

Other results pointing to the possible formation of less reactive mixed hydrates are those of $D_{3}$ and $D_{4}$ copolymerizations initiated by the monohydrate of the acid. ${ }^{9}$ There is a very slow reaction of $D_{3}$ giving mainly $D_{6}$ with initial rates about 100 times lower than for copolymerizations in anhydrous media. 
Even with an equimolar amount of $\mathrm{D}_{3}\left(\left[\mathrm{D}_{3}\right]_{0}=0.87 \mathrm{M} ;\left[\mathrm{D}_{4}\right]_{0}=0.98 \mathrm{M} ; \mathrm{CF}_{3} \mathrm{SO}_{3}{ }^{-}\right.$, $\left.\mathrm{H}_{3} \mathrm{O}^{+}=10^{-3} \mathrm{M}\right) 25$ hours are needed for a $95 \%$ conversion of $D_{3}$, and $D_{4}$ is apparently not consumed significantly. No polymer at all is formed at the beginning of the reaction, and low polymers are formed only after about 100 hours, whereas even in the slow polymerization of $\mathrm{D}_{4}$ with the hydrate, a high polymer was obtained after $25 \mathrm{~h}$. This shows that the inhibitory effect of water on $\mathrm{D}_{4}$ polymerization has been strongly enhanced by the presence of $D_{3}$, and may be explained by the possible complexation of an hydrate by $\mathrm{D}_{3}$, giving a species still reactive for $\mathrm{D}_{3}$ (but much less than the "free" acid) and inactive for $\mathrm{D}_{4}$.

\section{POSSIBLE ANALOGIES AND DIFFERENCES BETWEEN $D_{3}$ AND $\mathrm{D}_{4}$ POLYMERIZATION MECHANISMS}

In the kinetics of monomer consumption, an internal first order in monomer is observed for $\mathrm{D}_{3}$ and $\mathrm{D}_{4}$ and the apparent $k_{p}$ present similar features such as a high positive order (from 2.7 to 3 ) in $\left[\mathrm{CF}_{3} \mathrm{SO}_{3} \mathrm{H}\right]_{0}$ and a negative order in initial monomer concentration $(-0.8$ for $\mathrm{D}_{4},-1.8$ for $\mathrm{D}_{3}$ ).

The high order in acid probably results from similar reasons. We shall see that an order of 2 may be justified in various ways for the formation of active sites, but a higher order might result from the further intervention of the acid in the propagation step, such as propagation involving an activated monomer. The ester groups are the main products of the reaction of both $\mathrm{D}_{3}$ and $\mathrm{D}_{4}$ with triflic acid, but they have been shown to be inactive in the absence of excess acid. The various types of active species that may be considered in the cationic polymerization of cyclosiloxanes are ester or silanol activated by the acid, silanol or ester reacting with the activated monomer, or oxonium ions reacting with the monomer or with the activated monomer. ${ }^{6,7}$ We shall try to determine what types of species are more likely to be involved in the polymerizations of $\mathrm{D}_{3}$ and $\mathrm{D}_{4}$, but it seems that what will differ between these two monomers is the relative concentrations of the various species, since multiple equilibria are possible between them.

ester + acid $\rightleftarrows$ activated ester $\stackrel{\mathrm{D}_{x}}{\rightleftarrows}$ oxonium

Other equilibria may be considered involving the ester and the silanol:

$$
\begin{gathered}
\text { silanol }+ \text { acid } \rightleftarrows \text { activated silanol } \rightleftarrows \\
\mathrm{H}_{2} \mathrm{O}+\text { ester }
\end{gathered}
$$

For the whole reaction, the three main differences between $D_{3}$ and $D_{4}$ behavior have been shown to be the following:

\section{Cycles formation.}

With $\mathrm{D}_{3}$, the cycles are nearly exclusively of the $D_{3 x}$ type and are formed with a kinetic control up to high conversions, proportionally to the high polymer quantity. Their concentration is much higher than their equilibrium concentration and may even be higher than that of the polymer, according to the type of initiator used.

With $D_{4}$, the cycles are formed in the following decreasing concentrations: $D_{4}>D_{5}>D_{6}>$ $\mathrm{D}_{7} \cdots$, most likely through a back-biting mechanism, their concentration reaching slowly their equilibrium concentration.

If oxonium ions exist in these systems, their formation would be easier with $\mathrm{D}_{3}$ that would lead to more stable species than $D_{4}$, and the formation of $D_{3 \cdot x}$ cycles might result from ring expansion on the $\mathrm{D}_{3}^{+}$oxonium ions.

On the other hand, for $\mathrm{D}_{4}$ a silanol end group reacting with activated monomer would not explain the fast back-biting reaction observed, that would be more likely with an activated ester- (or a transitory sililenium ion) or even with oxonium species.

\section{Role of Water}

With both $\mathrm{D}_{3}$ and $\mathrm{D}_{4}$, there is a partial inhibition for ratios $\left[\mathrm{H}_{2} \mathrm{O}\right] /\left[\mathrm{CF}_{3} \mathrm{SO}_{3} \mathrm{H}\right]$ of 1 to 
2. For higher ratios (e.g., $\sim 10)$ there is a complete inhibition for $\mathrm{D}_{4}$ and a strong cocatalytic effect for $D_{4}$.

The inhibitory effect of water at low concentration shows that lower hydrates are less reactive than the "free" acid. The strong cocatalytic. effect of water in the $D_{3}$ case seems to mean that the higher hydrates are much more reactive (or "activating"). Since both $\mathrm{D}_{3 x}$ and polymer are formed rapidly and simultaneously, the activation by hydrated acid should occur for the two parallel reactions, that might both involve an activated monomer.

In order to understand the complete inhibition of high polymer formation and the low yields in cycles observed at high $\left[\mathrm{H}_{2} \mathrm{O}\right] /$ $\left[\mathrm{CF}_{3} \mathrm{SO}_{3} \mathrm{H}\right]$ ratios for $\mathrm{D}_{4}$, another mechanism should be considered, which is again the "activated ester" one.

\section{Molecular Weights}

For $\mathrm{D}_{3}$, they increase rapidly and linearly from the beginning up to high conversions which shows the presence of a constant number of growing chains. This agrees with a polymerization without termination or transfer and involving a constant number of end groups that may either be active or react with an activated monomer.

For $\mathrm{D}_{4}$, there is a small induction period for the formation of a low polymer (e.g., mol wt 10 to 20000) the concentration and mol wt of which remains approximately constant during most of the reaction, suggesting a quasistationary state for the active centers concentration. The high polymer is formed later, with a slow increase of mol wt with conversion. This has been assumed to result from a very slow hydrolysis, by higher hydrates of the acid, of the ester groups present at both ends of the low polymer, and from the heterocondensation of the ester groups in large excess with the silanol groups.

\section{MECHANISM AND KINETICS OF $\mathrm{D}_{4}$ POLYMERIZATION}

The kinetics have been described as resulting from a quasistationary state, ${ }^{4}$ initiation involving an ester group and an acid molecule. The latter is hydrated since water is in large excess over the acid (6 to $7 \mathrm{H}_{2} \mathrm{O}$ per acid), but initiation would necessitate a less hydrated acid in order to activate the ester. This less hydrated acid would be formed through hydrolysis of an ester group by a higher hydrate (eq 4).

If the formation of this acid is the rate determining step for initiation,

$$
R_{i}=R_{h}=k_{h}[-\mathrm{SiOTf}]\left[\mathrm{CF}_{3} \mathrm{SO}_{3} \mathrm{H}, n \mathrm{H}_{2} \mathrm{O}\right]
$$

It has been found that SiOTf and TfOH, $n \mathrm{H}_{2} \mathrm{O}$ concentrations are constant during the reaction, and since [TfOH, $\left.n \mathrm{H}_{2} \mathrm{O}\right]+[\mathrm{SiOTf}]=$ $[\mathrm{TfOH}]_{0}$, their molar fractions are respectively $f[\mathrm{TfOH}]_{0}$ and $(1-f)[\mathrm{TfOH}]_{0}$ so that the rate of formation of the less hydrated acid -and of the silanol- is:

$$
R_{i}=k_{\text {hyd. }} f(1-f)[\mathrm{TfOH}]_{0}^{2}
$$

If termination occurs by reaction with any siloxane unit present in the medium:

$$
R_{t}=k_{t}\left[\mathrm{P}^{*}\right]\left[\mathrm{D}_{4}\right]_{0}
$$

For a quasi-stationary state, if the acid produced by hydrolysis activates immediately an ester group, $k_{t}\left[\mathrm{P}^{*}\right]\left[\mathrm{D}_{4}\right]_{0}=k_{h} f(1-f)[\mathrm{TfOH}]_{0}^{2}$ and $\left[\mathrm{P}^{*}\right]_{\text {stat. }}=k_{h} f(1-f)[\mathrm{TfOH}]_{0}^{2} / k_{t}\left[\mathrm{D}_{4}\right]_{0}$. The $\overline{\mathrm{DP}}_{n}$ is given by:

$$
\overline{\mathrm{DP}}_{n}=R_{p} / R_{t}=k_{p}\left[\mathrm{P}^{*}\right]\left[\mathrm{D}_{4}\right] / k_{t}\left[\mathrm{P}^{*}\right]\left[\mathrm{D}_{4}\right]_{0}
$$

The $\overline{\mathrm{DP}}_{n}$ should be constant at the beginning and decrease with conversion. This is difficult to verify since condensations may occur simultaneously through the $\mathrm{SiOH}$ groups.

However, this scheme does not lead to the higher order in $[\mathrm{TfOH}]_{0}$, equal to 2.7 , found for the stationary rates of $D_{4}$ and $D_{6}$ polymerizations.

The explanation of this order near three is 
still conjectural. It has been supposed that the third order in $\left[\mathrm{CF}_{3} \mathrm{SO}_{3} \mathrm{H}\right]_{0}$ is resulting from an initiation involving a trimer, but that seems unlikely. Data on the conductivity of $\mathrm{CF}_{3} \mathrm{SO}_{3} \mathrm{H}$ in $\mathrm{CH}_{2} \mathrm{Cl}_{2}{ }^{23}$ have shown that the specific conductivity (at $-15^{\circ} \mathrm{C},[\mathrm{HA}]: 4$ to $\left.8 \times 10^{-4} \mathrm{M}\right)$ is proportional to the acid concentration. This is consistent with the formation of a small concentration of ions resulting from the self ionization of 2 acid molecules ("binary ionogenic equilibrium"):

$$
2 \mathrm{HA} \rightleftarrows \mathrm{H}_{2} \mathrm{~A}^{+}+\mathrm{A}^{-}
$$

but not with the dissociation of aggregates $[\mathrm{HA}]_{2}$ or $[\mathrm{HA}]_{3}$.

Another possibility might be that the formation of an active center necessitates the successive intervention of several acid molecules in order to give active centers with a counterion of the $\left(\mathrm{CF}_{3} \mathrm{SO}_{3}^{-}, 2 \mathrm{CF}_{3} \mathrm{SO}_{3} \mathrm{H}\right)$ type, as has been found in the polymerization of 1,1-diphenylethylene. ${ }^{22}$ However, this seems less likely with a silyl ether and particularly with $\mathrm{D}_{3}$ which should be sufficiently basic to compete for at least one acid molecule.

One may consider also a supplementary activation by the acid in the transition state, and this might result from a propagation involving a complexed "activated" monomer, $\left(\mathrm{D}_{4}, \mathrm{HA}\right)$ :

$$
\mathrm{P}^{*}+\mathrm{D}_{4}, \mathrm{HA} \longrightarrow \mathrm{PD}_{4}^{*}+\mathrm{HA}
$$

and to

$$
R_{p}=k\left[\mathrm{P}^{*}\right][\mathrm{HA}]\left[\mathrm{D}_{4}\right]
$$

What could be the end group reacting with the activated monomer? It might seem unlikely to be a $\mathrm{SiOH}$ since silanol addition was found to have the same effect as water ${ }^{3,4}$ (with one mole of disilanol instead of one mole of water), but the esterification of the silanol might be faster than initiation, giving immediately the equivalent water concentration and leaving a very low concentration of silanol in equilibrium. If propagation involves the monomer activated by the hydrated acid, it could take place with a slow rate on the very small concentration of $\mathrm{SiOH}$ groups present, leading to an approximate order of 3 for the acid concentration.

However, this last proposal does not seem satisfactory for various reasons. The main one is the existence of the back-biting reaction, that is not understood if growth occurs on a silanol end group. The second difficulty is the explanation of the cocatalytic effect of added triflic ester, which would not lead to a sufficient increase in acid concentration to justify the increase in rate observed with an equimolar amount of ester and acid. Moreover, if silanol was the reactive end group, it should not be inhibited by excess water. From these observations, one may conclude either that the initiation necessitates three acid molecules, but the mechanism remains unknown (see, however, next section on $\mathrm{D}_{3}$ ), or that the activation of the ester and of the monomer both take place, propagation involving a dipoledipole interaction such as:

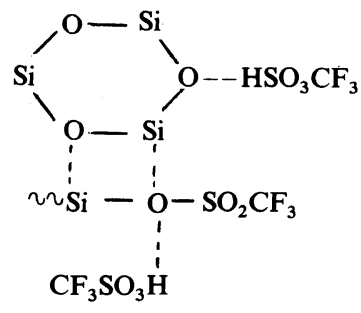

\section{MECHANISM AND KINETICS OF $D_{3}$ POLYMERIZATION}

From the variation of mol wt with conversion, it may be concluded that the reaction occurs either on a constant number of active centers formed rapidly at the beginning of the reaction, or on a constant number of endgroups reacting with an. activated monomer.

The simultaneous formation of polymer and cycles might result from two independent reactions occurring on two different types of active centers, or from two different reactions 
involving only one type of active center. We shall first examine the second possibility, for which the most qualified type of active center could be of the oxonium type, for which both propagation and ring expansion may be considered.

It should be acknowledged that siloxonium ions have never been observed, but their transitory existence has been assumd whatever is the monomer in order to explain the various reactions of siloxanes, and the one involving a $\mathrm{D}_{3}$ cycle would probably be the most stable in the dimethylcyclosiloxanes series.

With $D_{3}$ the initiation reaction giving the reactive groups or the active centers takes place very rapidly at the beginning. It might follow the still more rapid establishment of an equilibrium between $\mathrm{D}_{3}$ and the acid TfOH:

$$
\begin{gathered}
\mathrm{D}_{3}+\text { HOTf } \stackrel{K_{1}}{\rightleftharpoons} \mathrm{D}_{3}, \text { HOTf } \\
\left.\mathrm{D}_{3}, \text { HOTf }+ \text { HOTf } \stackrel{K_{1}}{\longrightarrow} \text { HOD }_{3} * \text { Tf, HOTf } \stackrel{\mathrm{D}_{3}}{\longrightarrow} \mathrm{HOD}_{3}-\stackrel{+}{\mathrm{O}_{3}}\right) \\
\left(\mathrm{TfO}^{-}, \text {HOTf }\right)
\end{gathered}
$$

Such a scheme may permit to explain a negative order of about -1 in $\left[D_{3}\right]_{0}$ for the active centers concentration, if $K_{1}$ is large, as it may be shown that $[\mathrm{HA}]=[\mathrm{HA}]_{0} /\left(1+K_{1}\left[\mathrm{D}_{3}\right]_{0}\right)$ and that

$$
R_{i}=k_{i} K_{1}\left[\mathrm{D}_{3}\right]_{0}\left\{[\mathrm{HA}]_{0}^{2} /\left(1+K_{1}\left[\mathrm{D}_{3}\right]_{0}\right)^{2}\right\}
$$

But it does not explain an order of -1.8 . One may consider the possible formation of higher complexes with $\mathrm{D}_{3}$ that would displace the equilibrium (5) towards the right with a de-

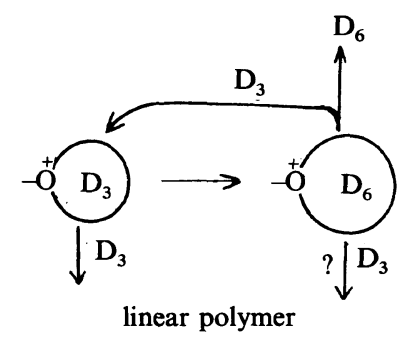

After an expansion giving the oxonium ions $\mathrm{D}_{6}^{+}$or $\mathrm{D}_{9}^{+}$, an exchange with the more basic $\mathrm{D}_{3}$ would give back the oxonium $\mathrm{D}_{3}^{+}$and yield $\mathrm{D}_{6}, \mathrm{D}_{9}$, etc. Simultaneously, propagation giving the linear polymer might occur, involving mainly $\mathrm{D}_{3}^{+}$. These two types of reactions may both correspond to an order in $\mathrm{D}_{3}$ equal to 1 if the exchange reaction is rapid compared to the ring expansion. crease in HOTf. But the order observed is difficult to justify quantitatively. An explanation based on the variation of the dielectric constant of the medium cannot justify the very large effect observed, and particularly the important difference with the behavior of $\mathrm{D}_{4}$.

Polymer formation might occur either on the oxonium side or on the $\mathrm{SiOH}$ side, or on both.

If we first consider ring-expansion on the oxonium side, we may have:

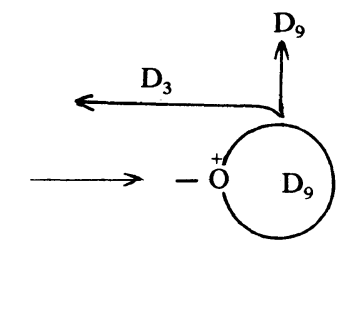

As already said for $\mathrm{D}_{4}$, the order 3 in acid may be justified in various ways but unfortunately there are no direct arguments in favor of the various hypothesis. The simplest would be if the active centers formation (e.g., oxonium ions) would necessitate 3 molecules of acid, two to obtain the ester complexed with acid and a third one necessary to have an ionization giving the oxonium. However, 
the existence of a counterion of the $\left(\mathrm{CF}_{3} \mathrm{SO}_{3}^{-}\right.$, $\left.2 \mathrm{CF}_{3} \mathrm{SO}_{3} \mathrm{H}\right)$ type is quite hypothetical in the presence of a large excess of $\mathrm{D}_{3}$. Another possibility would be that the third acid molecule is involved in the ring-expansion step, for example as an activating agent for the monomer. Since added water in large excess increases the rate, the highly hydrated acid would be more efficient as discussed earlier (see eq 3). But this does not fit with a similar high polymer formation involving the oxonium, for which the reactivity of the "activated" monomer should be less than that of $D_{3}$ for the nucleophilic attack on the oxonium.

The observation has also been made ${ }^{9}$ that the relative proportions of high polymer, $D_{6}$, $D_{9}$, etc. are changing with $\left[D_{3}\right]_{0}$. The weight ratio $[$ Polymer $] /\left[D_{6}\right]$ increases with $\left[\mathrm{D}_{3}\right]_{0}$, as does also the ratio $\left[D_{9}\right] /\left[D_{6}\right]$. One may imagine that the formation of polymer and $D_{9}$ is first order in monomer while that of $D_{6}$ is not. This might result from a strong solvation of $\mathrm{D}_{3}^{+}$by $D_{3}$. The association would not occur with the more bulky $\mathrm{D}_{6}^{+}$, explaining the first order dependence of $\mathrm{D}_{9}$ formation on $[\mathrm{D}]_{0}$. However, in order to keep the internal order in $D_{3}$ conversion still equal to 1 , it is the exchange reaction, giving $D_{6}$, which should be slow compared to the ring expansion (whereas that giving $D_{9}$ would be fast).

Another possibility cannot be excluded, which is a polymer growth on the other end of the macromolecule, on a $\mathrm{SiOH}$ or an ester group, that might occur either exclusively, or simultaneously with a growth involving the oxonium end. This would imply again an activated monomer mechanism, in order to explain the global order in acid concentration.

The possibility of growth on a silanol group for $D_{3}$ might result from a temporary protection of these groups from esterification if the lower water complexes involving $\mathrm{D}_{3}$ suggested above were not very reactive for this type of reaction. Growth on activated ester as suggested for $D_{4}$ cannot be completely ex- cluded either. But since the effect of water is quite different with $D_{3}$, this type of growth might occur only at low water concentration, and at high concentrations, growth would be on the silanol.

\section{REFERENCES}

1. J. Chojnowski, M. Scibiorek, and J. Kowalski, Makromol, Chem., 178, 1351 (1977).

2. J. Chojnowski and L. Wilczek, Makromol. Chem., 180, 117 (1979).

3. J. J. Lebrun, G. Sauvet, and P. Sigwalt, Makromol. Chem., Rapid Commun., 3, 752 (1982).

4. G. Sauvet, J. J. Lebrun, and P. Sigwalt in "Cationic Polymerization and Related Processes," E. J. Goethals, Ed., Academic Press, New York, N. Y., 1984, p 237.

5. L. Wilczek, S. Rubinsztajn, and J. Chojnowski, Makromol. Chem., 187, 39 (1986).

6. P. Sigwalt, L'actualité Chimique, No. 3, 45 (1986).

7. J. Chojinowski, S. Rubinsztajn, and L. Wilczek, L'actualité Chimique, No. 3, 86 (1986).

8. C. Gobin, M. Masure, G. Sauvet, and P. Sigwalt, Makromol. Chem. Macromol. Symp., 6, 237 (1986).

9. P. Nicol, M. Masure, and P. Sigwalt, to be published.

10. P. V. Wright in "Ring-Opening Polymerization," Vol. II, K. J. Ivin and T. Saegusa, Ed., Elsevier, London, 1984, Chapter 14, p 1055.

11. M. Jacobson and W. H. Stockmayer, J. Chem. Phys., 18, 1600 (1950).

12. K. Matyjaszewski, M. Zielinski, P. Kubisa, S. Slomkowski, J. Chojnowski, and S. Penczek, Makromol. Chem., 181, 1469 (1980).

13. W. Kühn, Kolloid. Z, 68, 2 (1934).

14. Z. Laita and M. Jelinek, Vysokomol. Soyedin. Ser. A., 4, 1739 (1962); Polym. Sci. USSR, 4, 535 (1963).

15. M. Masurek and J. Chojnowski, Makromol. Chem., 178, 1005 (1977).

16. T. Graczyk and Z. Lasocki, Bull. Acad. Polym. Sci. Sc. Chim., 26, 917 (1978) and ibid., 27, 285 (1979).

17. S. Penczek, P. Kubisa, and K. Matyjaszewski, $A d v$. Polym. Sci., 68/69, 42 (1985).

18. C. Gobin, thèse 3è cycle (Paris, 1986).

19. L. Wilczek and J. Chojnowski, Macromolecules, 14, 9 (1981).

20. L. Wilczek and J. Chojnowski, Makromol. Chem., 184, 77 (1983).

21. S. Kozuka, T. Kitamura, N. Kobayashi, and K. Ogino; Bull. Chem. Soc. Jpn., 52, 1950 (1979).

22. P. Sigwalt and G. Sauvet, Polym. J., 12, 651 (1980).

23. N. V. Ahmad and G. V. Schulz, Makromol. Chem. Rapid Commun., 1, 369 (1980). 